\title{
The Criminal Procedure (Scotland) Act 1995: new legislation for mentally disordered offenders
}

\author{
Derek Chiswick
}

The Criminal Procedure (Scotiond) Act 1995 came into force on 1 April 1996. If contains major new provisions in respect of defendants found insane, fogether with changes concerning other mentally disordered oflenders.

The Criminal Procedure (Scotland) Act 1995 consolidates various provisions from other Acts which have become law during the 20 years since its predecessor, the $1975 \mathrm{Act}$, was enacted. It thus contains, inter alia, the important provisions introduced in the Criminal Justice (Scotland) Act 1995 for dealing with defendants found insane, together with other enactments, already in operation, from the Criminal Justice (Scotland) Act 1980, the Mental Health (Amendment) (Scotland) Act 1983, and the Mental Health (Scotland) Act 1984. Psychiatrists in Scotland will need to familiarise themselves with the Criminal Procedure (Scotland) Act 1995 which took effect on 1 April 1996. This paper outlines the relevant contents for psychiatrists; full guidance is contained in Scottish Office Circular HD 6/1996.

Part VI of the 1995 Act (sections 52-63) contains the main provisions for dealing with mentally disordered defendants (See Table 1). The duplication of provisions for summary and solemn procedure contained in the 1975 Act has been discontinued: psychiatrists will no longer need to remember two sets of three-digit numbers. The provisions for interim hospital orders, hospital orders and guardianship are unchanged.

\section{Committal of accused (untried) defen- dant to hospital (section 52)}

Authority to commit an untried person suffering from mental disorder to hospital continues but there is now provision (section 52 (6)) for the court to vary or revoke the committal where there has been a change of circumstances. This might include the need to transfer a patient to a different hospital (e.g. the State Hospital), or to discharge him to court if the order is no longer required. Committal to hospital may not exceed 40 and 110 days respectively in summary and solemn proceedings.

\section{Insanity in bar of trial and at the time of the act (sections 54-56)}

Legal criteria for insanity in bar of trial and at the time of the act are unchanged. However, sweeping

Table 1. Criminal Procedure (Scotland) Act 1995: provisions for mentally disordered offenders

\begin{tabular}{lcc}
\hline Provision & CP(S)A 1995 & CP(S)A 1975 \\
\hline Committal of accused person to hospital & 52 & $25 \& 330$ \\
Disposal in cases of insanily & 57 & $174 \& 375$ \\
Remand for inquiry into mental condition & 200 & $180 \& 381$ \\
Interim hospltal order & 53 & $174 A \& 375 A$ \\
Hospltal order \& Guardianship & 58 & $175 \& 376$ \\
Restrictions on discharge & 59 & $178 \& 379$ \\
Admission to the State Hospital & $58(5)$ & $175(4) \& 376(7)$ \\
Probation order with treatment for mental condition & 230 & $184 \& 385$ \\
\hline
\end{tabular}


changes are introduced in line with some of the recommendations of the Thomson Report (Scottish Home and Health Department and Crown Office, 1975), and with the provisions of the Criminal Procedure (Insanity and Unfitness to Plead) Act 1991 for England and Wales. Two major innovations are an examination of the facts in cases of insanity in bar of trial, and a flexible disposal for all insanity cases. Insanity at the time of the act is a defence now available under summary procedure (section $54(6)$ ).

Defendants who might be insane in bar of trial will now be subject to a three stage procedure. First is a determination that they are (or are not) insane in bar of trial, second is an examination of the facts, and third is a decision on disposal. Where the court is satisfied on the evidence of two doctors, at least one of whom must be approved under section 20 of the 1984 Act, that the defendant is insane in bar of trial, it must record the finding, discontinue the trial and order an "examination of facts". The defendant may meanwhile be remanded in custody or on bail or be committed to hospital under a new temporary hospital order (section 54(1)(c)).

Rules of evidence and procedure at an examination of facts must "be as nearly as possible those applicable" in an ordinary trial (section 55 (6)); it is held normally in public before a sheriff or judge sitting alone. The court must be satisfied beyond reasonable doubt that the accused committed the act, and on the balance of probabilities that there are no grounds (e.g. selfdefence or alibi) for acquittal. If the court is not satisfied on both these matters, then it must acquit (and liberate) the accused. Compulsory hospital care, if appropriate, would require initiation under the civil provisions of the Mental Health (Scotland) Act 1984. Where the court acquits the defendant on the ground of insanity, disposal is as described below.

Novel disposals have been introduced for defendants who (i) are found insane in bar of trial and are found to have committed the act or (ii) are acquitted on the ground of insanity. For both these categories of insanity cases the court may make a hospital order with or without restrictions, or a guardianship order, or a new supervision and treatment order (para. 1(1) of Schedule 4), or make no order at all. An exception is where the charge is murder; here the mandatory disposal is a hospital order with restrictions on discharge without limit of time.

A supervision and treatment order places the person under the supervision of a social worker for a maximum period of 3 years with a requirement to submit to treatment under the direction of a doctor. The order may include a condition of residence in a place other than a hospital. A supervision and treatment order gives no authority to a social worker or doctor to enforce treatment and it contains no sanction in the event of non-compliance.

There is a right of appeal by a person found insane in bar of trial against the finding, the examination of the facts and the disposal (section 62). The prosecution may appeal on a point of law against a finding of insanity in bar of trial or at the time of the act, and against the disposal (section 63)

\section{Hospital and restriction orders, medical evidence}

The substance of these orders is unchanged (section 58). However, restriction orders (section 59) may only be made without limit of time. Written or oral evidence for the purpose of section 58 must include a statement indicating whether or not the doctor is related to the accused and whether he has any pecuniary interest in the disposal (section 61).

\section{Remand and committal for inquiry into mental condition (section 200)}

Detention in hospital of a convicted person prior to disposal is now available. Remand in prison or on bail for medical inquiry is still possible but in addition the court will be able to commit a convicted person to a hospital for three weeks (with possibility of extension by a further three weeks) for the purpose of a medical examination and report. The written or oral evidence of one medical practitioner is necessary. The court must send the hospital a statement of the reason for the inquiry and any information about the person's mental condition. The court may, with cause, vary the terms of the committal by substituting another hospital (e.g. the State Hospital). A person committed to hospital for inquiry into his mental condition has, within 24 hours, the right of appeal against such committal.

\section{Probation with a requirement for treatment for a mental condition (section 230)}

Probation with a requirement for treatment for a mental condition has been extended (section 230) to include treatment under the supervision of a chartered psychologist (defined in section 307 as a person listed in the British Psychological Society's Register of Chartered Psychologists). Other requirements are unchanged; these include a maximum duration of 12 months, an option of residence in a psychiatric hospital, 
supporting evidence from an "approved" doctor, and a requirement to satisfy the court that arrangements for the treatment have been made.

\section{Comment}

For many years Scotland has had enviable legislation for dealing with mentally disordered offenders in the criminal justice system and in the health service. The Criminal Procedure (Scotland) Act 1995 brings innovative change and also smooths some problematical rough edges. It cannot be said that mentally disordered offenders in Scotland are denied care or treatment through any impediments in the law. What is now needed is a combination of infrastructure and resources to make effective the laws that Parliament has seen fit to give us.

\section{Reference}

Scottish Home and Health Departiment and Crown Office (1975) Criminal Procedure in Scotland, 2nd Report (Thomson) Cmnd 6218. Edinburgh: HMSO.

Derek Chiswick, Consultant Forensic Psychiatrist, Edinburgh Healthcare NHS Trust, Royal Edinburgh Hospital, Morningside Place, Edinburgh EH $105 \mathrm{HF}$

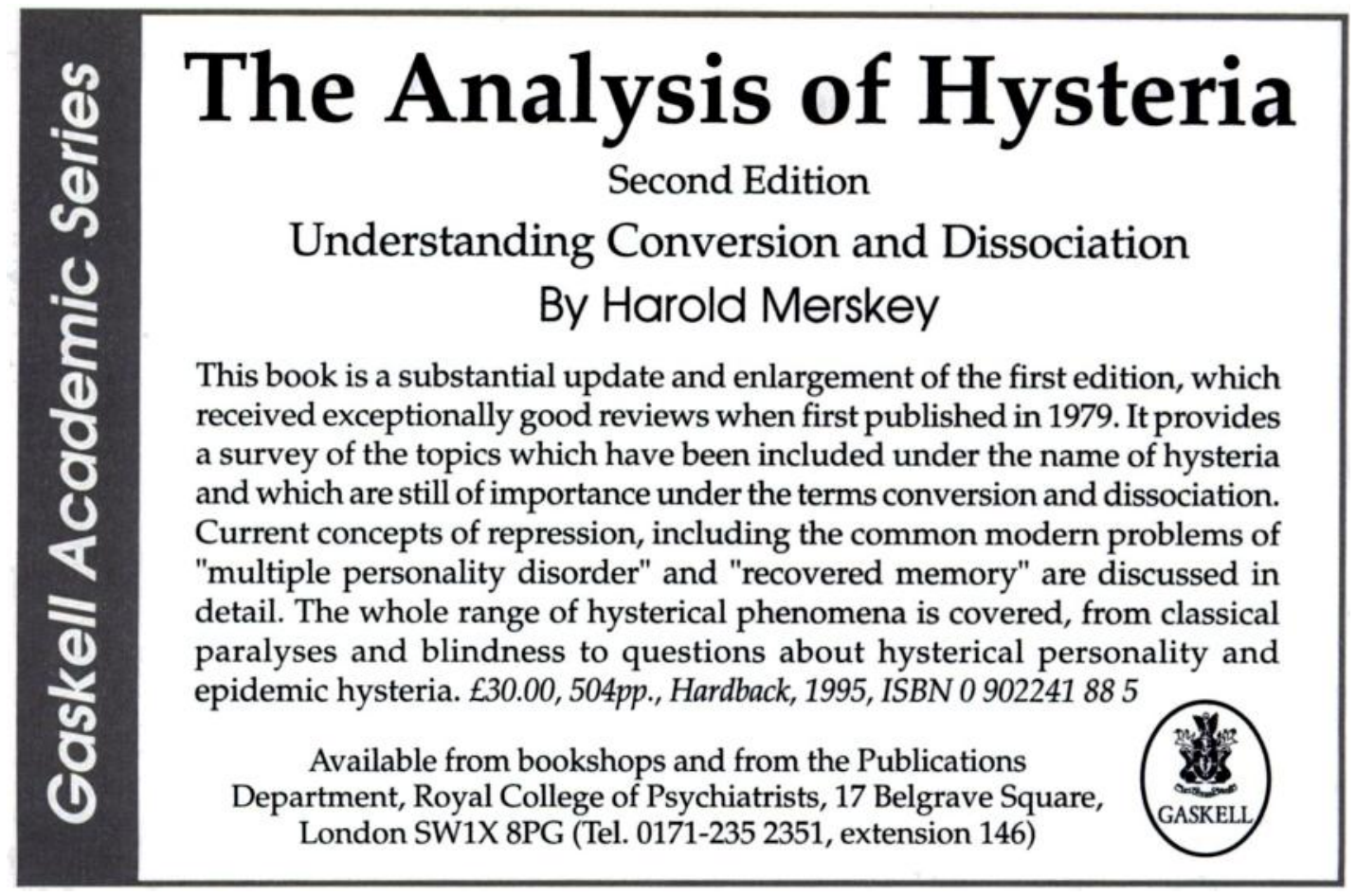

